\title{
Article \\ Perfect Absorption and Refractive-Index Sensing by Metasurfaces Composed of Cross-Shaped Hole Arrays in Metal Substrate
}

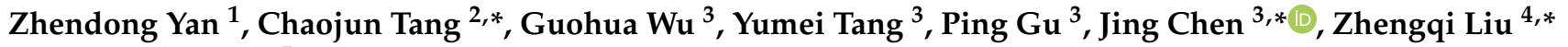 \\ and Zhong Huang 5
}

check for

updates

Citation: Yan, Z.; Tang, C.; Wu, G.; Tang, Y.; Gu, P.; Chen, J.; Liu, Z.;

Huang, Z. Perfect Absorption and

Refractive-Index Sensing by

Metasurfaces Composed of

Cross-Shaped Hole Arrays in Metal

Substrate. Nanomaterials 2021, 11, 63.

https://doi.org/10.3390/nano11010063

Received: 25 November 2020

Accepted: 26 December 2020

Published: 29 December 2020

Publisher's Note: MDPI stays neutral with regard to jurisdictional clai$\mathrm{ms}$ in published maps and institutional affiliations.

Copyright: (C) 2020 by the authors. Licensee MDPI, Basel, Switzerland. This article is an open access article distributed under the terms and conditions of the Creative Commons Attribution (CC BY) license (https:// creativecommons.org/licenses/by/ $4.0 /)$.
1 College of Science, Nanjing Forestry University, Nanjing 210037, China; zdyan@njfu.edu.cn

2 Center for Optics and Optoelectronics Research, Collaborative Innovation Center for Information Technology in Biological and Medical Physics, College of Science, Zhejiang University of Technology, Hangzhou 310023, China

3 College of Electronic and Optical Engineering, Nanjing University of Posts and Telecommunications, Nanjing 210023, China; 1219023306@njupt.edu.cn (G.W.); 1219023305@njupt.edu.cn (Y.T.); guping@njupt.edu.cn (P.G.)

4 College of Physics Communication and Electronics, Jiangxi Normal University, Nanchang 330022, China

5 College of Physics and Electronic Engineering, Jiangsu Second Normal University, Nanjing 210013, China; huangzhong89@126.com

* Correspondence: chaojuntang@zjut.edu.cn (C.T.); jchen@njupt.edu.cn (J.C.); zliu@jxnu.edu.cn (Z.L.)

\begin{abstract}
Achieving perfect electromagnetic wave absorption with a sub-nanometer bandwidth is challenging, which, however, is desired for high-performance refractive-index sensing. In this work, we theoretically study metasurfaces for sensing applications based on an ultra-narrow band perfect absorption in the infrared region, whose full width at half maximum (FWHM) is only $1.74 \mathrm{~nm}$. The studied metasurfaces are composed of a periodic array of cross-shaped holes in a silver substrate. The ultra-narrow band perfect absorption is related to a hybrid mode, whose physical mechanism is revealed by using a coupling model of two oscillators. The hybrid mode results from the strong coupling between the magnetic resonances in individual cross-shaped holes and the surface plasmon polaritons on the top surface of the silver substrate. Two conventional parameters, sensitivity $(S)$ and figure of merit (FOM), are used to estimate the sensing performance, which are $1317 \mathrm{~nm} / \mathrm{RIU}$ and 756, respectively. Such high-performance parameters suggest great potential for the application of label-free biosensing.
\end{abstract}

Keywords: perfect absorption; refractive-index sensing; metasurfaces

\section{Introduction}

Recently, there is increasing interesting in studying the perfect absorption of electromagnetic waves for refractive-index sensing by employing metasurfaces [1-32], metallic nanostructures [33-61], and graphene nanostructures [62-71], in violet [62], visible [1-5,33-43,63,64], infrared [6-17,44-57,65], terahertz (THz) [18-24,58-61,66-71], and gigahertz (GHz) $[25,26]$ frequency regions. In artificial metasurfaces, magnetic resonance is able to induce a substantial magnetic dipole to interact with the magnetic field of incident electromagnetic waves, and thus produce an effective permeability [72]. When the impedance of artificial metasurfaces is matched with that of vacuum, the incident electromagnetic waves will be nearly completely absorbed at a certain frequency range [72]. At present, most reported metasurfaces for perfect absorption and sensing are usually composed of a periodic array of metal nanoparticles with various shapes on the top surface of a dielectric film that is deposited on a metal substrate [1-26]. For example, Cong et al. demonstrated experimentally the metasurface electromagnetic wave perfect absorber, which consists of a square array of cross-shaped aluminum nanoparticles on a polyimide spacer supported on a 
very thick aluminum layer [19]. The remarkable enhancement of electromagnetic fields at the magnetic dipolar resonance enables a very strong interaction with the analyte for ultrasensitive sensing scheme in $\mathrm{THz}$ frequencies.

For metal nanostructures, the well-known surface plasmon resonances or the other resonance modes are able to result into the huge electromagnetic field enhancement, which can be also utilized for the perfect absorption and refractive-index sensing [33-61]. For example, Shi et al. theoretically studied a multi-band perfect absorber for sensing application in visible and near-infrared regions, which is based on the excitations of localized surface plasmons, delocalized surface plasmon polaritons, and lattice plasmon resonances, in the periodic arrays of gold nanodisks with a prismatic hole standing on silica/gold bilayer films [36]. Bhattarai et al. experimentally investigated the refractiveindex sensing in near-infrared region, when the perfect absorption is obtained by FabryPerot cavity mode in the periodic arrays of gold elliptical nanodisks lifted by dielectric pillars on gold substrate [46].

From mid-infrared to $\mathrm{THz}$ frequencies, nanostructured graphene is capable of supporting surface plasmon resonances [73], because graphene has an effective permittivity of standard Drude model. The plasmon resonances of graphene nanostructures have narrower bandwidths due to their low damping rates and, thus, result into stronger electromagnetic field confinement, as compared with those in metal nanostructures [74]. More importantly, the positions of the plasmon resonances graphene can be tuned via bias voltage [75]. These properties make nanostructured graphene a good candidate for perfect absorption and sensing application [62-71]. For example, Yi et al. propose a graphene-based plasmonic sensor with dual-band perfect absorption in infrared region, for the periodically arranged graphene nanorings to be placed on the silica film deposited on the gold substrate [69]. The position of dual-band perfect absorption can be shifted by applying an external voltage on graphene to manipulate the Femi energy, which is favorable for more flexible sensing applications.

The change of the refractive index of the environment medium will lead to the obvious shift of the positions of surface plasmon resonances or magnetic resonances, and the corresponding spectral intensity such as transmission and reflection will also undergo a change. This is the fundamental physical mechanism of the refractive-index sensing. The major advantage of perfect absorption for sensing is that a very small change of the refractive index is able to be detected [10], because the spectral position and intensity will exhibit a dramatic change if the utilized resonance mode has a narrow bandwidth and a strong enhancement of electromagnetic fields. However, as pointed out recently by Yong et al. [56], simultaneous achieving the ultra-narrow band perfect absorption and the very large enhancement of electromagnetic fields is challenging, owing to the fast radiative damping of the resonance mode and the intrinsic Ohmic loss in metals.

In this work, we numerically demonstrate an ultra-narrow band perfect absorption with a significant electromagnetic field enhancement in near-infrared region, whose FWHM is only $1.74 \mathrm{~nm}$. The ultra-narrow band perfect absorption results from the hybrid mode of magnetic resonance and surface plasmon polaritons in metasurfaces composed of a periodic array of cross-shaped holes in a silver substrate. The resonant position of the hybrid mode can be predicted well by using a coupling model of two oscillators. Numerical results show that two conventional performance parameters for sensing, $S$ and $F O M$, have very high values of $1317 \mathrm{~nm} / \mathrm{RIU}$ and 756, respectively, which suggests great potential for the application of label-free biosensing.

\section{Methods}

In Figure 1, we schematically show the unit cell of our studied metasurfaces, which are composed of a periodic array of cross-shaped holes drilled in a silver substrate. The length, width, and depth of the cross-shaped holes are $l, w$, and $d$, respectively, as indicated by the arrowed lines. The array periods along the $x$-axis direction and the $y$-axis direction are $p_{x}$ and $p_{y}$, respectively. The light (electromagnetic) wave is supposed to be normally incident 
from top to bottom. The electric field $\left(\boldsymbol{E}_{i n}\right)$, the magnetic field $\left(\boldsymbol{H}_{i n}\right)$, and the wave vector $(\boldsymbol{k})$ of incident light are along the $x$-axis direction, the $y$-axis direction, and the negative $z$-axis direction, respectively, as indicated by three arrows in the left upper corner. In this work, we will use the commercial software package "EastFDTD" [https: / www.eastfdtd.com] to calculate the absorption spectra and the electromagnetic field distributions. In numerical simulations, the silver film has a finite thickness of $500 \mathrm{~nm}$. The calculated absorption spectra are completely the same, provided that the silver film is enough thick and thus the incident light could not pass through it. Even if the silver film with sufficient thickness is supposed to be deposited on a dielectric substrate, the calculated absorption spectra are still the same, because the incident light is not able penetrate the silver film to feel the existent of the dielectric substrate. Periodic boundary condition is applied to the $x$ and $y$-axis directions, and perfectly matched layer is set along the $z$-axis direction. For numerical convergence, the mesh size $\Delta s$ is taken to be 5 and $50 \mathrm{~nm}$ in the cross-shaped hole and the other region, respectively. The time step is $\Delta t=\Delta s / 2 c$, where $c$ is light speed in vacuum. More information about the commercial software package can be found at the website (https:/ / www.eastfdtd.com). In our calculations, experimental data are used for the wavelength-dependent real and imaginary parts of complex refractive index of silver substrate [76]. The proposed metasurfaces can be experimentally fabricated by focused ion beam (FIB) lithography. The commonly used FIB setup (Strata FIB 201, FEI Company, Hillsboro, OR, USA) is able to mill the proposed array of cross-shaped holes on a silver film on a quartz substrate. The thick silver film is firstly deposited on a quartz substrate by electron beam evaporation before the process of the FIB lithography. The linear optical response of reflection $(\mathrm{R})$ of our proposed metasurfaces is measured experimentally by using a commercial Fourier-transform infrared spectrometer (FTIR, Nicolet 6700) equipped with a polarizer. Then, the absorption (A) obtained in experiment is equal to $1-R$.

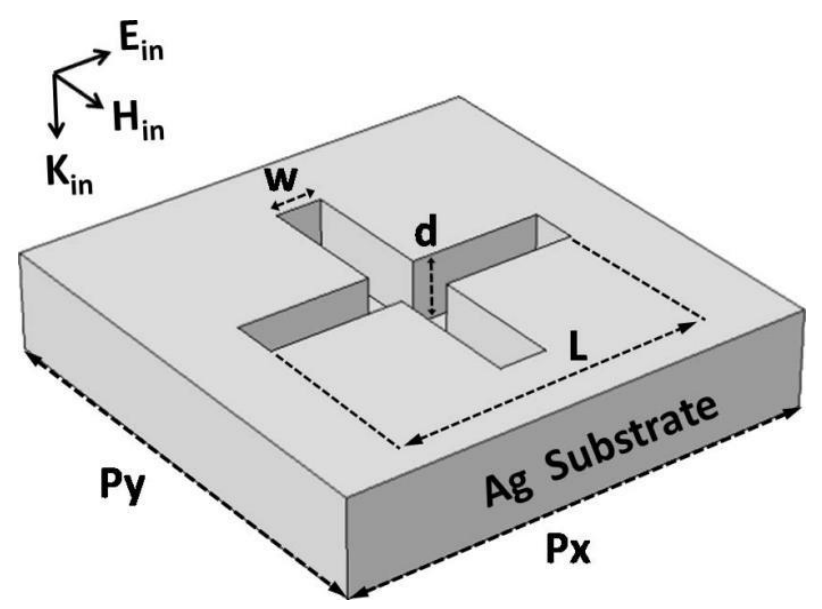

Figure 1. Schematic of the building block of metasurfaces for perfect absorption and refractiveindex sensing.

\section{Results and Discussion}

In Figure 2a, we show the numerically calculated absorption spectra at normal incidence, with the array periods $p_{x}=p_{y}=800 \mathrm{~nm}$ and the geometrical size of the cross-shaped holes $L=500 \mathrm{~nm}, d=200 \mathrm{~nm}$, and $w=50 \mathrm{~nm}$. An absorption peak is clearly seen, which is centered at the wavelength of $\lambda_{1}=1045 \mathrm{~nm}$. To reveal the physics of the absorption peak, in Figure $2 b$ we show the current distributions at the wavelength of $\lambda_{1}$ on the $x z$ plane with $y=-125 \mathrm{~nm}$. Obviously, the currents near the cross-shaped hole are relatively stronger, and create a loop on the $x z$ plane, as indicated by the red arrows in Figure $2 \mathrm{~b}$. The current loop will produce a substantial magnetic moment, which is able to response to the magnetic field of incident light, and thus form a magnetic resonance [77]. The magnetic resonance is the physical origin of the absorption peak centered at the wavelength of $\lambda_{1}$. 
The forming mechanism of the magnetic resonance is very similar to that in the U-shape metallic split-ring-resonators (SRRs). In order to better understand the magnetic resonance, in Figure 3 we have plotted electric and magnetic field distributions at the wavelength of $\lambda_{1}$ on three planes. In Figure $3 a, b$, the $x y$ plane with $z=0$ is just on the top surface of the silver substrate. In Figure $3 c, d$, the $x y$ plane with $z=-100 \mathrm{~nm}$ is at the geometrical center of the cross-shaped hole. In Figure $3 \mathrm{e}, \mathrm{f}$, the $x z$ plane with $y=-125 \mathrm{~nm}$ is along the white dotted line in Figure 3a.
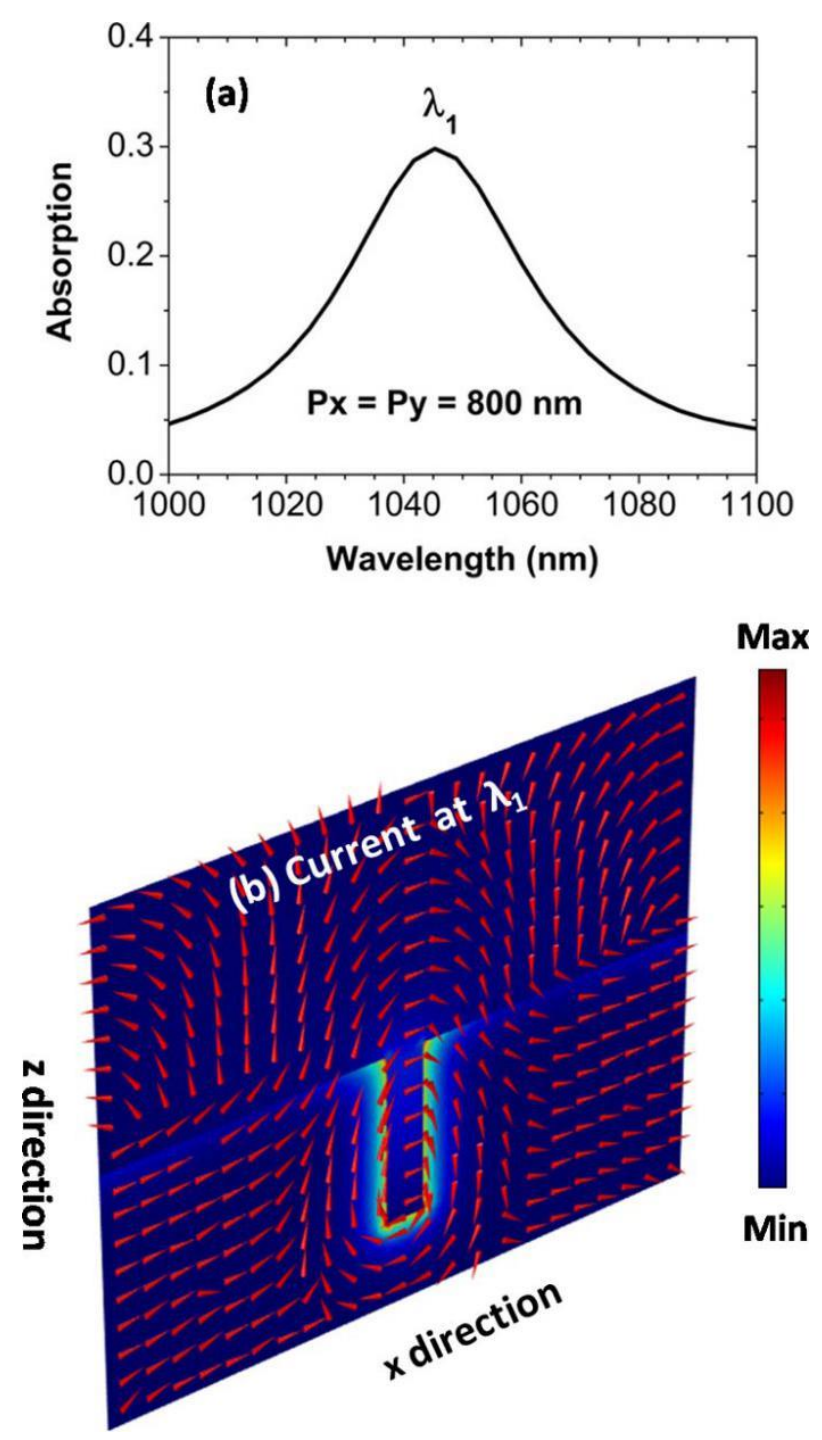

Figure 2. (a) Numerically calculated absorption spectra at normal incidence, with geometrical parameters of $p_{x}=p_{y}=800 \mathrm{~nm}, L=500 \mathrm{~nm}, d=200 \mathrm{~nm}$, and $w=50 \mathrm{~nm}$. (b) Current distributions at the wavelength of $\lambda_{1}$ on the $x z$ plane along the white dotted line in Figure 3a. The colors represent the current strength, and the red arrows give the current directions. 

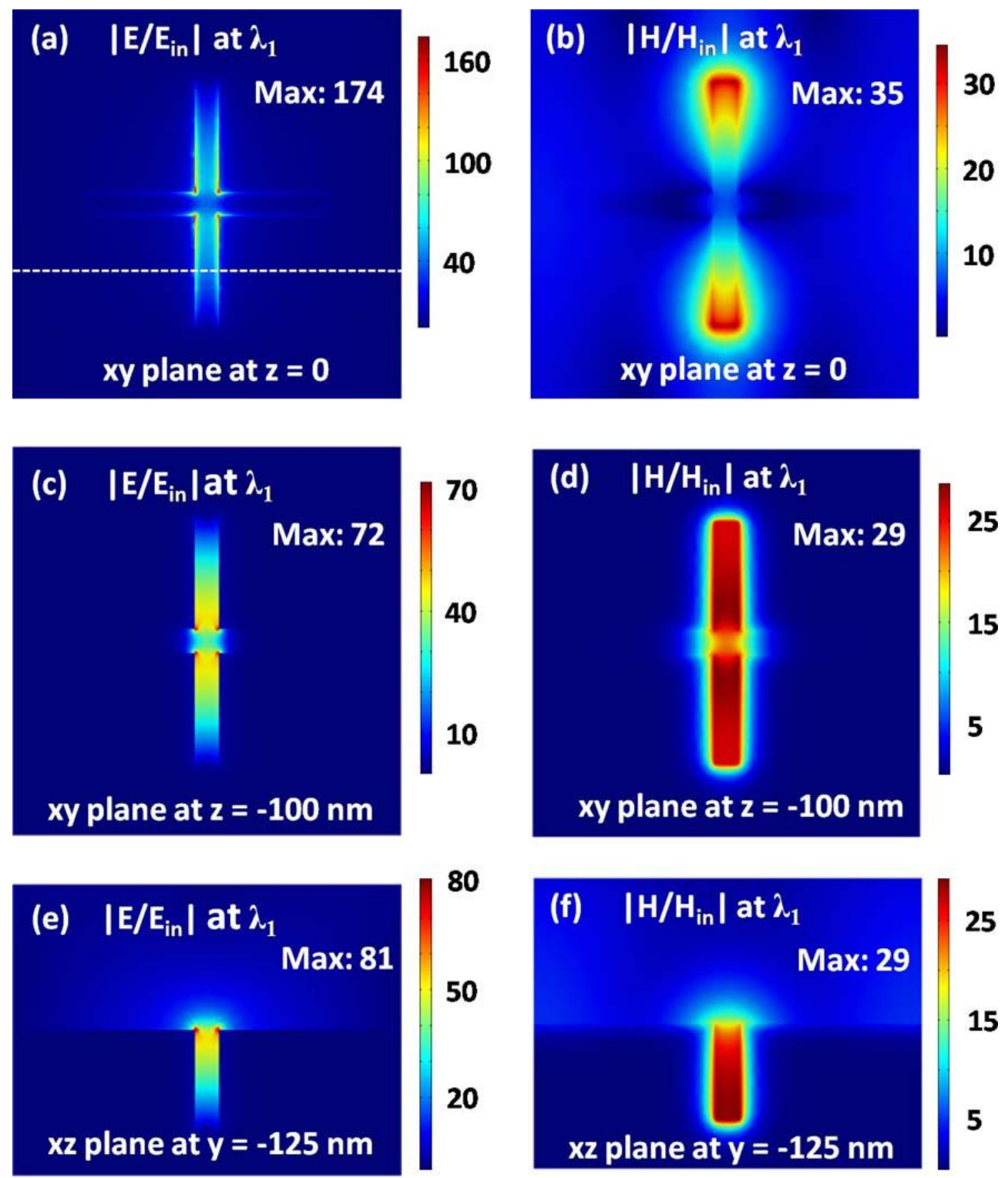

Figure 3. Electric (a,c,e) and magnetic $(\mathbf{b}, \mathbf{d}, \mathbf{f})$ field strength at the resonance wavelength of $\lambda_{1}$. The $x y$ plane with $z=0(\mathbf{a}, \mathbf{b})$ is just on the top surface of the metal substrate. The $x y$ plane with $z=-100 \mathrm{~nm}$ $(\mathbf{c}, \mathbf{d})$ is at the geometrical center of the cross-shaped hole. The $x z$ plane with $y=-125 \mathrm{~nm}(\mathbf{e}, \mathbf{f})$ is along the white dotted line in (a).

In Figure $4 \mathrm{a}$, we present a series of absorption spectra at normal incidence, for the array periods of both $p_{x}$ and $p_{y}$ to be increased from 1000 to $1550 \mathrm{~nm}$ in steps of $50 \mathrm{~nm}$. For each period, there is a very sharp absorption peak, which red-shifts when the array periods are increased. Figure $4 \mathrm{~b}$ shows the dependence of the maximum value at the absorption peak on the array period. At a proper period of $1300 \mathrm{~nm}$, the nearly perfect absorption more than $99.7 \%$ is achieved. Away from the period of $1300 \mathrm{~nm}$, the peak value will decrease quickly. The FWHM of the absorption peak for different periods is exhibited in Figure 4c. With the increasing period, the absorption peak becomes more and more narrow, whose FWHM can be reduced from about $16 \mathrm{~nm}$ to even $0.65 \mathrm{~nm}$. For the perfect absorption peak, the FWHM is about $1.74 \mathrm{~nm}$. Achieving such a perfect absorption peak with an extremely narrow bandwidth is desired for high-performance sensing applications. 

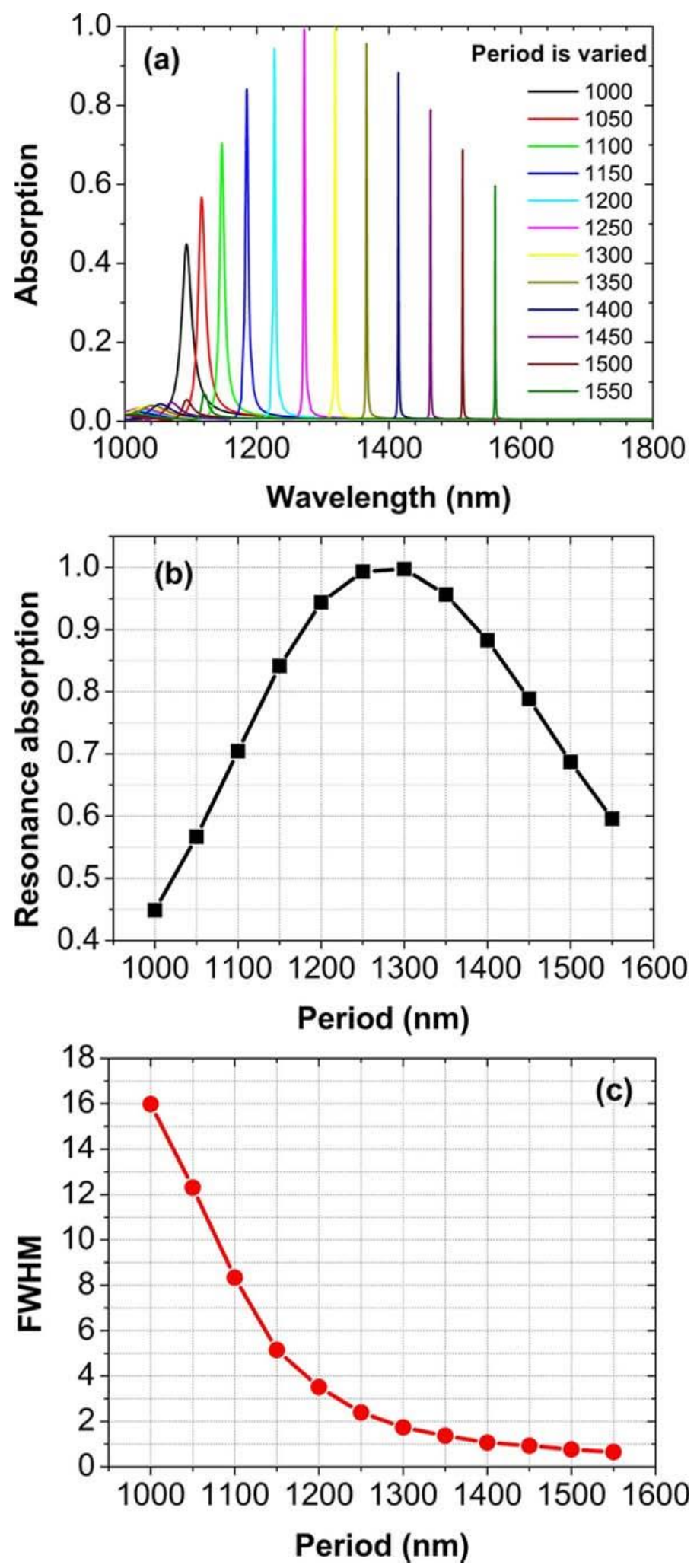

Figure 4. (a) Normal-incidence absorption spectra for the period $\left(p_{x}=p_{y}\right)$ to be varied from 1000 to $1550 \mathrm{~nm}$ in steps of $50 \mathrm{~nm}$. (b,c) Maximum value and FWHM of absorption peak for different periods, respectively.

Next, we will prove that the sharp absorption peak in Figure 4a is related to a hybrid mode, which results from the coupling between magnetic resonance localized within the 
cross-shaped hole and surface plasmon polaritons propagating on the top surface of the silver substrate. A coupling model of two oscillators can be used to calculate the energy of the hybrid mode [78], and the computing formula is:

$$
E_{+,-}=\left(E_{\mathrm{MR}}+E_{\mathrm{SPP}}\right) / 2 \pm \sqrt{\Delta / 2+\left(E_{\mathrm{MR}}-E_{\mathrm{SPP}}\right)^{2} / 4}
$$

The energy of magnetic resonance, $E_{M R}$, is $1.1866 \mathrm{eV}$, corresponding to the wavelength of $\lambda_{1}=1045 \mathrm{~nm}$. The energy of surface plasmon polaritons, $E_{S P P}$, can be analytically obtained for different periods [79]. In Figure 5, we have compared the positions of absorption peaks for different periods with the resonance wavelengths of the hybrid mode predicted by the above theoretical model with the coupling strength $\Delta=0.008 \mathrm{eV}$. Obviously, they are in an excellent agreement.

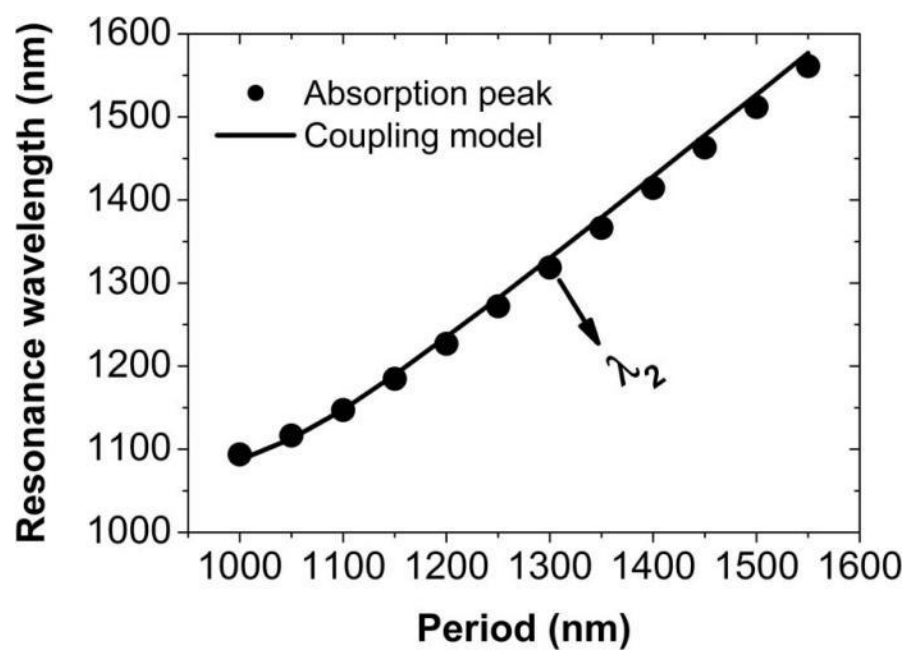

Figure 5. Comparison of the positions of absorption peaks with those predicted by the coupling model of two oscillators.

To further understand the property of the hybrid mode, in Figure 6 we plot the distributions of electric and magnetic fields at the resonance wavelength $\lambda_{2}=1318.7 \mathrm{~nm}$ of the perfect absorption with the array periods $p_{x}=p_{y}=1300 \mathrm{~nm}$. The positions of three planes in Figure 6 are the same as those in Figure 3, but the array periods are different. The electromagnetic fields in Figure 6 get stronger on all three planes, as compared with those in Figure 3. Since the magnetic resonance is a localized mode associated with the cross-shaped hole, so the electromagnetic fields in Figure 3 are mainly distributed into the hole. However, for the hybrid mode we also observe the regular distribution pattern of electromagnetic field enhancement on the top surface of the silver substrate, as clearly seen in Figure $6 a, b, e, f$. The regular distribution pattern is very prominent in Figure $6 \mathrm{e}, \mathrm{f}$, which suggests the excitation of surface plasmon polaritons propagating on the silver surface [79]. The distribution property of electromagnetic fields further confirms that the sharp absorption peak origins from the hybrid mode, due to the coupling of magnetic resonance with surface plasmon polaritons. It is well known that surface plasmon polaritons have a slow radiation damping [79], and so the bandwidth of the hybrid mode is very narrow. The maximum amplitudes of electric and magnetic fields are 208 and 76 times of those of the incident light, respectively. Correspondingly, the maximum intensities of electric and magnetic fields, which are the square of amplitude, can be enhanced to 43,264 and 5776 times of those of the incident light. Such a high enhancement of electromagnetic fields is comparable with the values reported recently [56], which is helpful for sensing applications. 

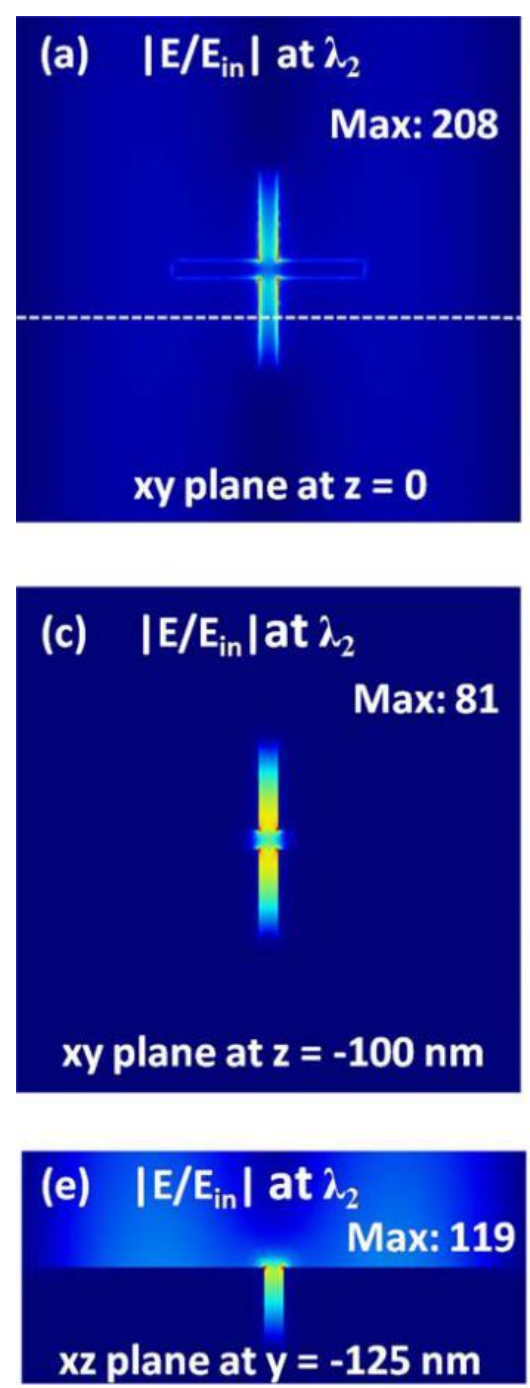

200

120

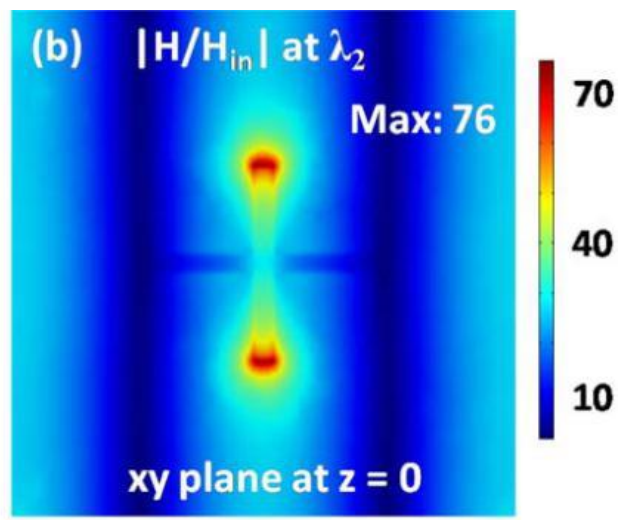

80

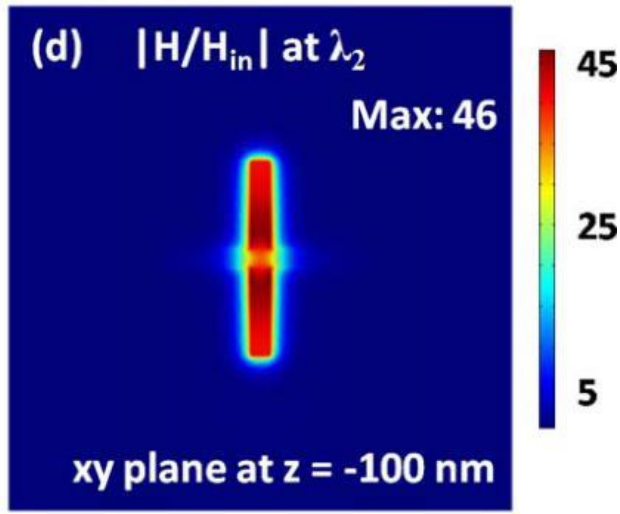

100

60

20

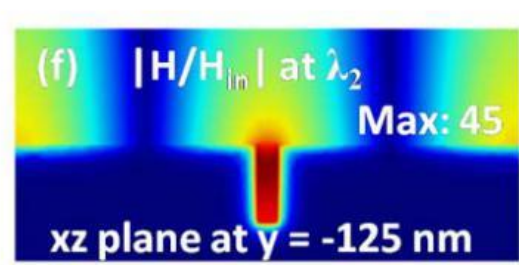

Figure 6. Electric (a,c,e) and magnetic $(\mathbf{b}, \mathbf{d}, \mathbf{f})$ field strength at the resonance wavelength of $\lambda_{2}$. The $x y$ plane with $z=0(\mathbf{a}, \mathbf{b})$ is just on the top surface of the metal substrate. The $x y$ plane with $z=-100 \mathrm{~nm}$ $(\mathbf{c}, \mathbf{d})$ is at the geometrical center of the cross-shaped hole. The $x z$ plane with $y=-125 \mathrm{~nm}(\mathbf{e}, \mathbf{f})$ is along the white dotted line in (a).

To study the potential sensing applications of our studied nanostructures, in Figure $7 \mathrm{a}$ we show a series of absorption spectra at normal incidence with the array periods $p_{x}$ $=p_{y}=1300 \mathrm{~nm}$, for the refractive index of surrounding medium is varied from 1.0 to 1.1 in steps of 0.02 . When the refractive index of surrounding medium is increased slightly, the absorption peak will shift obviously, which is very sensitive to the change of the refractive index. Figure $7 \mathrm{~b}$ shows the dependence of the position of the absorption peak on the refractive index. Conventionally, two important parameters, sensitivity $(S)$ and figure of merit (FOM), are widely used to estimate the sensing performance [80-84]. $S$ and FOM can be defined as:

$$
S=\Delta \lambda / \Delta n, F O M=S / F W H M
$$

where $\Delta \lambda$ is the spectral shift of the absorption peak, $\Delta n$ is the change of the refractive index, and FWHM is the full width at half maximum of the perfect absorption peak. In our case, $S=1317 \mathrm{~nm} / \mathrm{RIU}$, which is the slope of the black line in Figure $7 \mathrm{~b}$. The FWHM of the perfect absorption peak is only $1.74 \mathrm{~nm}$, so we achieve an ultra-high FOM of about 756. These two values of performance parameters are very high, which are far larger than those reported recently in many papers. In Table 1, we give $S$ and FOM of sensors based 
on perfect absorption in the near-infrared region. The dephasing time of the hybrid mode, defined as $2 \hbar / F W H M[85]$, is about $1.2 \times 10^{-25} \mathrm{~s}$.
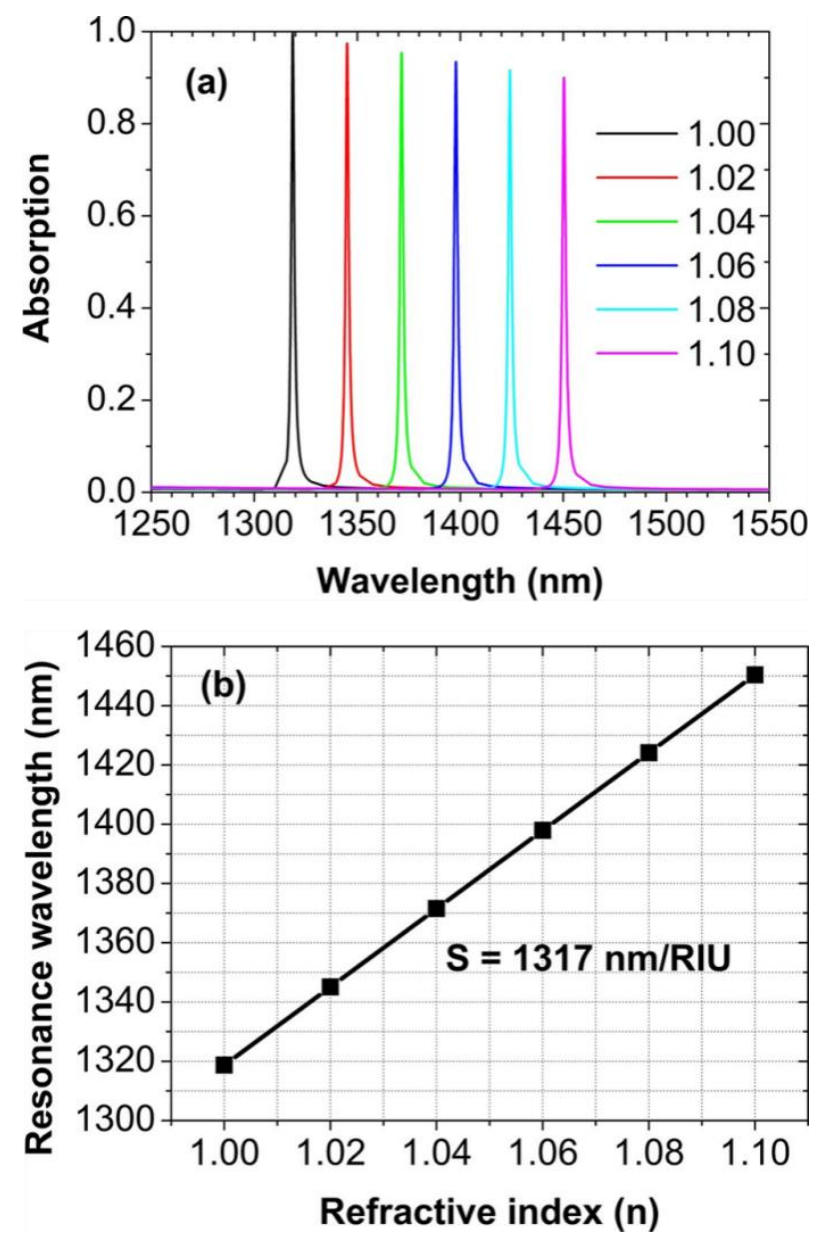

Figure 7. (a) Normal-incidence absorption spectra with the refractive index $(n)$ of surrounding medium increased from 1.0 to 1.1 in steps of 0.02 . (b) The position of absorption peak for different $n$.

Table 1. Performance of sensors based on perfect absorption in the near-infrared region.

\begin{tabular}{cccc}
\hline References & $\lambda(\mathbf{n m})$ & $\boldsymbol{S}$ (nm/RIU) & FOM (RIU-1) \\
\hline$[12]$ & 1711 & 1240.8 & 123.45 \\
{$[13]$} & 2103 & 1445 & 28.8 \\
{$[14]$} & 1649 & 260.4 & 2.91 \\
{$[49]$} & 1728 & 900 & 15 \\
{$[50]$} & 1159 & 959 & 16.54 \\
{$[54]$} & 1536 & 150 & 25 \\
{$[55]$} & 1541 & 1170 & 1054 \\
{$[56]$} & 918 & 885 & 110 \\
{$[57]$} & 907 & 991 & 124 \\
This work & 1318 & 1317 & 756 \\
\hline
\end{tabular}

\section{Conclusions}

In summary, we have studied theoretically metasurfaces for high-performance refractiveindex sensing based on the ultra-narrowband perfect absorption of electromagnetic waves in infrared region. The studied metasurfaces are composed of a periodic array of cross-shaped holes in a silver substrate. The ultra-narrow band perfect absorption results from a hybrid mode, due to the coupling between the magnetic resonances localized within individual cross-shaped holes and the surface plasmon polaritons propagating on the top surface 
of the silver substrate. Numerical results show a high sensitivity $(S)$ of $1317 \mathrm{~nm} / \mathrm{RIU}$ and a large figure of merit (FOM) reaching to 756 , which suggests great potential for the application of label-free biosensing.

Author Contributions: Z.Y.: Writing—original draft, supervision, project administration, writing—review and editing. C.T.: Writing —original draft, supervision, project administration, writing—review and editing. G.W.: Writing—review and editing. Y.T.: Writing—review and editing. P.G.: Writing—original draft, supervision, project administration, writing —review and editing. J.C.: Writing—original draft, supervision, project administration, writing — review and editing. Z.L.: Writing—original draft, supervision, project administration, writing — review and editing. Z.H.: Writing—review and editing. All authors have read and agreed to the published version of the manuscript.

Funding: This work is financially supported by the National Natural Science Foundation of China (NSFC) (11974188, 11704183, 11704184, 11904139, 61705197, 11304159, and 11104136), the Natural Science Foundation of Zhejiang Province (LY14A040004), the project funded by China Postdoctoral Science Foundation (2018M632345), the Qing Lan Project of Jiangsu Province, and the NUPTSF (NY218022).

Data Availability Statement: All data have been illustrated in the manuscript and in the supplementary material.

Conflicts of Interest: The authors declare that we have no financial and personal relationships with other people or organizations that can inappropriately influence our work, there is no professional or other personal interest of any nature or kind in any product, service and/or company that could be construed as influencing the position presented in, or the review of, the manuscript entitled, "Perfect Absorption and Refractive-Index Sensing by Metamaterials Composed of Cross-Shaped Hole Arrays in Metal Substrate".

\section{References}

1. Zheng, X.X.; Xiao, Z.Y.; Ling, X.Y. Broadband visible perfect absorber for sensor based on ultra-thin metamaterial. J. Mater. Sci. Mater. Electron. 2017, 28, 7739-7744. [CrossRef]

2. Tittl, A.; Mai, P.; Taubert, R.; Dregely, D.; Liu, N.; Giessen, H. Palladium-based plasmonic perfect absorber in the visible wavelength range and its application to hydrogen sensing. Nano Lett. 2010, 11, 4366-4369. [CrossRef] [PubMed]

3. Cheng, Y.Z.; Chen, F.; Luo, H. Triple-band perfect light absorber based on hybrid metasurface for sensing application. Nanoscale Res. Lett. 2020, 15, 103. [CrossRef] [PubMed]

4. Cheng, Y.Z.; Luo, H.; Chen, F.; Gong, R.Z. Triple narrow-band plasmonic perfect absorber for refractive index sensing applications of optical frequency. OSA Continuum 2019, 2, 2113-2122. [CrossRef]

5. Hossaina, M.J.; Faruquea, M.R.I.; Ahmedb, M.R.; Alama, M.J.; Islamc, M.T. Polarization-insensitive infrared-visible perfect metamaterial absorber and permittivity sensor. Results Phys. 2019, 14, 102429. [CrossRef]

6. Lan, G.L.; Jin, Z.X.; Nong, J.P.; Luo, P.; Guo, C.C.; Sang, Z.G.; Dong, L.; Wei, W. Narrowband perfect absorber based on dielectric-metal metasurface for surface-enhanced infrared sensing. Appl. Sci. 2020, 10, 2295. [CrossRef]

7. Lari, E.S.; Vafapour, Z. Optically tunable triple-band perfect absorber for nonlinear optical liquids sensing. IEEE Sens. J. 2020, 20, 10130-10137. [CrossRef]

8. Vafapour, Z. Polarization-independent perfect optical metamaterial absorber as a glucose sensor in food industry applications. IEEE T. Nanobiosci. 2019, 18, 622-627. [CrossRef]

9. Lu, X.Y.; Wan, R.G.; Liu, F.; Zhang, T.Y. High-sensitivity plasmonic sensor based on perfect absorber with metallic nanoring structures. J. Mod. Opt. 2016, 63, 177-183. [CrossRef]

10. Liu, N.; Mesch, M.; Weiss, T.; Hentschel, M.; Giessen, H. Infrared perfect absorber and its application as plasmonic sensor. Nano Lett. 2010, 10, 2342-2348. [CrossRef]

11. Cheng, F.; Yang, X.D.; Gao, J. Enhancing intensity and refractive index sensing capability with infrared plasmonic perfect absorbers. Opt. Lett. 2014, 39, 3185-3188. [CrossRef] [PubMed]

12. Alipour, A.; Mir, A.; Farmani, A. Ultra high-sensitivity and tunable dual-band perfect absorber as a plasmonic sensor. Opt. Laser Technol. 2020, 127, 106201. [CrossRef]

13. Cheng, Y.Z.; Mao, X.S.; Wu, C.J.; Wu, L.; Gong, R.Z. Infrared non-planar plasmonic perfect absorber for enhanced sensitive refractive index sensing. Opt. Mater. 2016, 53, 195-200. [CrossRef]

14. Madadi, Z.; Abedi, K.; Darvish, G.; Khatir, M. An infrared narrow-band plasmonic perfect absorber as a sensor. Optik 2019, 183, 670-676. [CrossRef]

15. Ni, B.; Wang, Z.Y.; Zhao, R.S.; Ma, X.Y.; Xing, Z.Q.; Yang, L.S.; Huang, L.J.; Lin, Y.Y.; Zhang, D.B. Realisation of a humidity sensor based on perfect metamaterial absorber. Opt. Quant. Electron. 2017, 49, 33. [CrossRef] 
16. Madadi, Z.; Abedi, K.; Darvish, G.; Khatir, M. Dual-wavelength plasmonic perfect absorber suitable for refractive index sensing. Plasmonics 2020, 15, 703-708. [CrossRef]

17. Tung, N.T.; Tanaka, T. Characterizations of an infrared polarization-insensitive metamaterial perfect absorber and its potential in sensing applications. Photonic. Nanostruct. 2018, 28, 100-105. [CrossRef]

18. Wang, B.X.; Zhai, X.; Wang, G.Z.; Huang, W.Q.; Wang, L.L. A novel dual-band terahertz metamaterial absorber for a sensor application. J. Appl. Phys. 2015, 117, 014504. [CrossRef]

19. Cong, L.Q.; Tan, S.Y.; Yahiaoui, R.; Yan, F.P.; Zhang, W.L.; Singh, R. Experimental demonstration of ultrasensitive sensing with terahertz metamaterials absorbers: A comparison with the metasurfaces. Appl. Phys. Lett. 2015, 106, 031107. [CrossRef]

20. Yao, Y.; Li, S.P.; Zhu, L.; Wu, F.M.; He, X.J.; Jiang, J.X. Multi-band terahertz metamaterial absorber for sensing application. Integr. Ferroelectr. 2018, 190, 149-155. [CrossRef]

21. Bai, R.; Jin, X.R.; Zhang, Y.Q.; Zhang, S.; Lee, Y. Narrow-dual-band perfect absorption plasmonic sensor in metamaterials based on the coupling of two resonators. J. Nonlinear Opt. Phys. 2016, 25, 1650027. [CrossRef]

22. Wang, B.X.; Wang, G.Z.; Sang, T. Simple design of novel triple-band terahertz metamaterial absorber for sensing application. J. Phys. D Appl. Phys. 2016, 49, 165307. [CrossRef]

23. Hu, X.; Xu, G.Q.; Wen, L.; Wang, H.C.; Zhao, Y.C.; Zhang, Y.X.; Cumming, D.R.S.; Chen, Q. Metamaterial absorber integrated microfluidic terahertz sensors. Laser Photonics Rev. 2016, 10, 962-969. [CrossRef]

24. Janneh, M.; de Marcellis, A.; Palange, E.; Tenggara, A.T.; Byun, D. Design of a metasurface-based dual-band Terahertz perfect absorber with very high $Q$-factors for sensing applications. Opt. Commun. 2018, 416, 152-159. [CrossRef]

25. Akgol, O.; Karaaslan, M.; Unal, E.; Sabah, C. Implementation of a perfect metamaterial absorber into multi-functional sensor applications. Mod. Phys. Lett. B 2017, 31, 1750176. [CrossRef]

26. Bakir, M.; Karaaslany, M.; Dincery, F.; Akgolz, O.; Sabah, C. Electromagnetic energy harvesting and density sensor application based on perfect metamaterial absorber. Int. J. Mod. Phys. B 2016, 30, 1650133. [CrossRef]

27. Srivastava, Y.K.; Ako, R.T.; Gupta, M.; Bhaskaran, M.; Sriram, S.; Singh, R. Terahertz sensing of $7 \mathrm{nmdielectric} \mathrm{film} \mathrm{with} \mathrm{bound}$ states in the continuum metasurfaces. Appl. Phys. Lett. 2019, 115, 151105. [CrossRef]

28. Ahmadivand, A.; Gerislioglu, B.; Ahuja, R.; Mishra, Y.K. Terahertz plasmonics: The rise of toroidal metadevices towards immunobiosensings. Mater. Today 2020, 32, 108-130. [CrossRef]

29. Gerislioglu, B.; Dong, L.L.; Ahmadivand, A.; Hu, H.T.; Nordlander, P.; Halas, N.J. Monolithic metal dimer-on-film structure: New plasmonic properties introduced by the underlying metal. Nano Lett. 2020, 20, 2087-2093. [CrossRef]

30. Hasan, D.; Lee, C.K. Hybrid metamaterial absorber platform for sensing of $\mathrm{CO}_{2}$ gas at Mid-IR. Adv. Sci. 2018, 5, 1700581. [CrossRef]

31. Kenanakis, G.; Shen, N.H.; Mavidis, C.; Katsarakis, N.; Kafesaki, M.; Soukoulis, C.M.; Economou, E.N. Microwave and THz sensing using slab-pair-based metamaterials. Physica B 2012, 407, 4070-4074. [CrossRef]

32. Chen, T.; Li, S.Y.; Sun, H. Metamaterials application in sensing. Sensors 2012, 12, 2742-2765. [CrossRef] [PubMed]

33. Bagheri, S.H.; Strohfeldt, N.; Sterl, F.; Berrier, A.; Tittl, A.; Giessen, H. Large-area low-cost plasmonic perfect absorber chemical sensor fabricated by laser interference lithography. ACS Sens. 2016, 1, 1148-1154. [CrossRef]

34. Kim, S. Nearly perfect absorption by bimetallic surface plasmonic crystal and its application as sensor. IEEE Photonics Technol. Lett. 2014, 26, 1259-1262.

35. Cui, W.L.; Peng, W.; Yu, L.; Luo, X.L.; Gao, H.X.; Chu, S.W.; Masson, J.F. Hybrid nanodisk film for ultra-narrowband filtering, near-perfect absorption and wide range sensing. Nanomaterials 2019, 9, 334. [CrossRef]

36. Shi, L.L.; Shang, J.S.; Liu, Z.Q.; Li, Y.Y.; Fu, G.L.; Liu, X.S.; Pan, P.P.; Luo, H.M.; Liu, G.Q. Ultra-narrow multi-band polarizationinsensitive plasmonic perfect absorber for sensing. Nanotechnology 2020, 31, 465501. [CrossRef]

37. Wu, D.; Li, R.F.; Liu, Y.M.; Yu, Z.Y.; Yu, L.; Chen, L.; Liu, C.; Ma, R.; Ye, H. Ultra-narrow band perfect absorber and its application as plasmonic sensor in the visible region. Nanoscale Res. Lett. 2017, 12, 427. [CrossRef]

38. Yang, W.H.; Zhang, C.; Sun, S.; Jing, J.; Song, Q.; Xiao, S. Dark plasmonic mode based perfect absorption and refractive index sensing. Nanoscale 2017, 9, 8907-8912. [CrossRef]

39. Cai, W.J.; Zhang, Y.C.; Cai, S.H.; Wang, X.P.; Wu, J.; Yin, C.; Zhang, X.J.; Yuan, W.; Kuang, Q.Q.; Luo, H.M.; et al. Achieving the polarization-manipulated multispectral perfect absorption and sensitive sensing via a metal/insulator/metal elliptical nanocavity array. Opt. Rev. 2020, 27, 346-351. [CrossRef]

40. Jamali, A.A.; Witzigmann, B. Plasmonic perfect absorbers for biosensing applications. Plasmonics 2014, 9, 1265-1270. [CrossRef]

41. Mandal, P. Plasmonic perfect absorber for refractive index sensing and SERS. Plasmonics 2016, 11, 223-229. [CrossRef]

42. Liu, X.S.; Fu, G.L.; Liu, M.L.; Liu, G.Q.; Liu, Z.Q. High-Quality Plasmon Sensing with excellent intensity contrast by dual narrow-band light perfect absorbers. Plasmonics 2017, 12, 65-68. [CrossRef]

43. Liu, X.S.; Fu, G.L.; Zhan, X.F.; Liu, Z.Q. All-metal resonant metamaterials for one-, two-, three-band perfect light absorbers and sensors. Plasmonics 2019, 14, 967-971. [CrossRef]

44. Mayerhöfer, T.G.; Knipper, R.; Hübner, U.; Cialla-May, D.; Weber, K.; Meyer, H.G.; Popp, J. Ultra sensing by combining extraordinary optical transmission with perfect absorption. ACS Photonics 2015, 2, 1567-1575. [CrossRef]

45. ElKabbash, M.; Sreekanth, K.V.; Alapan, Y.; Kim, M.; Cole, J.; Fraiwan, A.; Letsou, T.; Li, Y.D.; Guo, C.L.; Sankaran, R.M.; et al. Hydrogen sensing using thin-film perfect light absorber. ACS Photonics 2019, 6, 1889-1894. [CrossRef] 
46. $\quad$ Bhattarai, K.; Ku, Z.; Silva, S.; Jeon, J.; Kim, J.O.; Lee, S.J.; Urbas, A.; Zhou, J.F. A large-area, mushroom-capped plasmonic perfect absorber: Refractive index sensing and Fabry-Perot cavity mechanism. Adv. Optical Mater. 2015, 3, 1779-1786. [CrossRef]

47. Liu, Z.Q.; Yu, M.D.; Huang, S.; Liu, X.S.; Wang, Y.; Liu, M.L.; Pan, P.P.; Liu, G.Q. Enhancing refractive index sensing capability with hybrid plasmonic-photonic absorbers. J. Mater. Chem. C 2015, 3, 4222-4226. [CrossRef]

48. Shi, L.L.; Tang, Q.; Liu, Z.Q.; Liu, Y.; Li, Y.Y.; Liu, G.Q.; Li, L. Tunable dual-band plasmonic perfect absorber and its sensing applications. J. Opt. Soc. Am. B 2019, 36, 2750-2756. [CrossRef]

49. Nejat, M.; Nozhat, N. Sensing and switching capabilities of a tunable GST-based perfect absorber in near-infrared region. J. Phys. D Appl. Phys. 2020, 53, 245105. [CrossRef]

50. Cheng, Y.Z.; Zhang, H.S.; Mao, X.S.; Gong, R.Z. Dual-band plasmonic perfect absorber based on all-metal nanostructure for refractive index sensing application. Mater. Lett. 2018, 219, 123-126. [CrossRef]

51. Wu, D.; Liu, Y.M.; Li, R.F.; Chen, L.; Ma, R.; Liu, C.; Ye, H. Infrared perfect ultra-narrow band absorber as plasmonic sensor. Nanoscale Res. Lett. 2016, 11, 483. [CrossRef] [PubMed]

52. Li, R.F.; Wu, D.; Liu, Y.M.; Yu, L.; Yu, Z.Y.; Ye, H. Infrared plasmonic refractive index sensor with ultra-high figure of merit based on the optimized all-metal grating. Nanoscale Res. Lett. 2017, 12, 1. [CrossRef] [PubMed]

53. Liu, Y.; Zhang, Y.Q.; Jin, X.R.; Zhang, S.; Lee, Y.P. Dual-band infrared perfect absorber for plasmonic sensor based on the electromagnetically induced reflection-like effect. Opt. Commun. 2016, 371, 173-177. [CrossRef]

54. Lu, X.Y.; Zhang, L.X.; Zhang, T.Y. Nanoslit-microcavity-based narrow band absorber for sensing applications. Opt. Express 2015, 23, 20715-20720. [CrossRef]

55. Luo, S.W.; Zhao, J.; Zuo, D.L.; Wang, X.B. Perfect narrow band absorber for sensing applications. Opt. Express 2016, 24, 9288-9294. [CrossRef]

56. Yong, Z.D.; Zhang, S.L.; Gong, C.S.; He, S.L. Narrow band perfect absorber for maximum localized magnetic and electric field enhancement and sensing applications. Sci. Rep. 2016, 6, 24063. [CrossRef]

57. Chen, J.; Nie, H.; Tang, C.J.; Cui, Y.H.; Yan, B.; Zhang, Z.Y.; Kong, Y.R.; Xu, Z.J.; Cai, P.G. Highly sensitive refractive-index sensor based on strong magnetic resonance in metamaterials. Appl. Phys. Express 2019, 12, 052015. [CrossRef]

58. Yahiaoui, R.; Tan, S.Y.; Cong, L.Q.; Singh, R.J.; Yan, F.P.; Zhang, W.L. Multispectral terahertz sensing with highly flexible ultrathin metamaterial absorber. J. Appl. Phys. 2015, 118, 083103. [CrossRef]

59. Tapsanit, P. Optimization of an extremely high Q-factor terahertz perfect absorber for environmental refractive index sensing using quasi-analytical solutions. J. Opt. Soc. Am. B 2020, 37, 2913-2922. [CrossRef]

60. Yan, F.; Li, Q.; Tian, H.; Wang, Z.W.; Li, L. An ultrahigh Q-factor dual-band terahertz perfect absorber with a dielectric grating slit waveguide for sensing. J. Phys. D Appl. Phys. 2020, 53, 235103. [CrossRef]

61. Wang, B.X.; Huang, W.Q.; Wang, L.L. Ultra-narrow terahertz perfect light absorber based on surface lattice resonance of a sandwich resonator for sensing applications. RSC Adv. 2017, 7, 42956-42963. [CrossRef]

62. Yan, Z.D.; Zhu, Q.; Wan, M.J.; Lu, X.; Pu, X.T.; Tang, C.J.; Yu, L.L. Graphene ultraviolet ultrahigh-Q perfect absorption for nanoscale optical sensing. Optics Express 2020, 28, 6095-6101. [CrossRef]

63. Li, C.W.; Qiu, J.L.; Ou, J.Y.; Liu, Q.H.; Zhu, J.F. High-sensitivity refractive index sensors using coherent perfect absorption on graphene in the Vis-NIR region. ACS Appl. Nano Mater. 2019, 2, 3231-3237. [CrossRef]

64. Long, Y.B.; Li, Y.X.; Shen, L.; Liang, W.Y.; Deng, H.D.; Xu, H.T. Dually guided-mode-resonant graphene perfect absorbers with narrow bandwidth for sensors. J. Phys. D: Appl. Phys. 2016, 49, 32LT01. [CrossRef]

65. Cen, C.L.; Chen, Z.Q.; Xu, D.Y.; Jiang, L.Y.; Chen, X.F.; Yi, Z.; Wu, P.H.; Li, G.F.; Yi, Y.G. High quality factor, high sensitivity metamaterial graphene-perfect absorber based on critical coupling theory and impedance matching. Nanomaterials 2020, 10, 95. [CrossRef] [PubMed]

66. Nejat, M.; Nozhat, N. Ultrasensitive THz refractive index sensor based on a controllable perfect MTM absorber. IEEE Sens. J. 2019, 19, 10490-10497. [CrossRef]

67. Li, J.; Liao, Q.H.; Li, H.M.; Liu, W.X.; Yu, T.B.; Wang, T.B. Tunable dual-band perfect metamaterial absorber based on monolayer graphene arrays as refractive index sensor. Jpn. J. Appl. Phys. 2020, 59, 095002. [CrossRef]

68. Nejat, M.; Nozhat, N. Sensing and switching capabilities of a graphene-based perfect dual-band metamaterial absorber with analytical methods. J. Opt. Soc. Am. B 2020, 37, 1359-1366. [CrossRef]

69. Yi, Z.; Liang, C.P.; Chen, X.F.; Zhou, Z.G.; Tang, Y.J.; Ye, X.; Yi, Y.G.; Wang, J.Q.; Wu, P.H. Dual-band plasmonic perfect absorber based on graphene metamaterials for refractive index sensing application. Micromachines 2019, 10, 443. [CrossRef]

70. Yi, Z.; Huang, J.; Cen, C.L.; Chen, X.F.; Zhou, Z.G.; Tang, Y.J.; Wang, B.Y.; Yi, Y.G.; Wang, J.; Wu, P.H. Nanoribbon-ring cross perfect metamaterial graphene multi-band absorber in THz range and the sensing application. Results Phys. 2019, $14,102367$. [CrossRef]

71. Qi, Y.P.; Zhang, Y.; Liu, C.Q.; Zhang, T.; Zhang, B.H.; Wang, L.Y.; Deng, X.Y.; Bai, Y.L.; Wang, X.X. A tunable terahertz metamaterial absorber composed of elliptical ring graphene arrays with refractive index sensing application. Results Phys. 2020, 16, 102012. [CrossRef]

72. Watts, C.M.; Liu, X.L.; Padilla, W.J. Metamaterial electromagnetic wave absorbers. Adv. Mater. 2012, 24, OP98-OP120. [CrossRef] [PubMed]

73. Papasimakis, N.; Thongrattanasiri, S.; Zheludev, N.I.; de Abajo, F.J.G. The magnetic response of graphene split-ring metamaterials. Light Sci. Appl. 2013, 2, e78. [CrossRef] 
74. Zheng, Z.B.; Li, J.T.; Ma, T.; Fang, H.L.; Ren, W.C.; Chen, J.; She, J.C.; Zhang, Y.; Liu, F.; Chen, H.J.; et al. Tailoring of electromagnetic field localizations by two-dimensional graphene nanostructures. Light Sci. Appl. 2017, 6, e17057. [CrossRef]

75. Qi, Y.P.; Zhang, Y.; Liu, C.Q.; Zhang, T.; Zhang, B.H.; Wang, L.Y.; Deng, X.Y.; Wang, X.X.; Yu, Y. A tunable terahertz metamaterial absorber composed of hourglass-shaped graphene arrays. Nanomaterials 2020, 10, 533. [CrossRef]

76. Johnson, P.B.; Christy, R.W. Optical constants of the noble metals. Phys. Rev. B 1972, 6, 4370-4379. [CrossRef]

77. Li, D.M.; Kuang, X.Y.; Zhang, H.; Liang, Y.Z.; Xu, T.; Qing, L.Y.; Zhu, Y.H.; Zhang, S.; Wang, W.X.; Wang, W. Experimental demonstration of high sensitivity refractive index sensing based on magnetic plasmons in a simple metallic deep nanogroove array. Opt. Express 2018, 26, 34122-34130. [CrossRef]

78. Bonnand, C.; Plenet, J.C.; Bréhier, A.; Parashkov, R.; Lauret, J.S.; Deleporte, E.; Bellessa, J. Particularities of surface plasmon-exciton strong coupling with large Rabi splitting. New J. Phys. 2008, 10, 065017.

79. Zayats, A.V.; Smolyaninov, I.I.; Maradudin, A.A. Nano-optics of surface plasmon polaritons. Phys. Rep. 2005, 408, 131-314. [CrossRef]

80. Ermatov, T.; Noskov, R.E.; Machnev, A.A.; Gnusov, I.; Atkin, V.; Lazareva, E.N.; German, S.V.; Kosolobov, S.S.; Zatsepin, T.S.; Sergeeva, O.V.; et al. Multispectral sensing of biological liquids with hollow-core microstructured optical fibres. Light Sci. Appl. 2020, 9, 173. [CrossRef]

81. Wang, X.X.; Zhu, J.K.; Tong, H.; Yang, X.D.; Wu, X.X.; Pang, Z.Y.; Yang, H.; Qi, Y.P. A theoretical study of a plasmonic sensor comprising a gold nano-disk array on gold film with a $\mathrm{SiO}_{2}$ spacer. Chin. Phys. B 2019, 28, 044201. [CrossRef]

82. Zhu, J.K.; Wang, X.X.; Wu, Y.; Su, Y.W.; Jia, T.X.; Yang, H.; Zhang, L.P.; Qi, Y.P.; Wen, X.L. Plasmonic refractive index sensors based on one- and two-dimensional gold grating on a gold film. Photonic Sens. 2020, 10, 375-386. [CrossRef]

83. Chau, Y.F.C.; Chen, K.H.; Chiang, H.P.; Lim, C.M.; Huang, H.J.; Lai, C.H.; Kumara, N.T.R.N. Fabrication and characterization of a metallic-dielectric nanorod array by nanosphere lithography for plasmonic sensing application. Nanomaterials 2019, 9, 1691. [CrossRef] [PubMed]

84. Farcau, C.; Marconi, D.; Colnita, A.; Brezestean, I.; Barbu-Tudoran, L. Gold nanopost-shell arrays fabricated by nanoimprint lithography as a flexible plasmonic sensing platform. Nanomaterials 2019, 9, 1519. [CrossRef]

85. Ahmadivand, A.; Gerislioglu, B.; Ramezani, Z. Gated graphene island-enabled tunable charge transfer plasmon terahertz metamodulator. Nanoscale 2019, 11, 8091-8095. [CrossRef] [PubMed] 